НАУКОВИЙ ВІСНИК

Scientific messenger of Lviv National University of
Veterinary Medicine and Biotechnologies

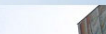

$\sqrt{3}$

RIES: VETERINARY SCIEN
Науковий вісник Аьвівського національного університету ветеринарної медицини та біотехнологій імені С.3. Гжицького. Серія: Ветеринарні науки

Scientific Messenger of Lviv National University of Veterinary Medicine and Biotechnologies. Series: Veterinary sciences

UDC 619:636.7:591.111:616.98

\title{
Integrated indices as a criterion for evaluation of the level of endogenous intoxication for leptospirosis in dogs
}

\author{
M. Radzikhovskyi ${ }^{1}$, V. Nedosekov ${ }^{1}$, O. Dyshkant ${ }^{2}$, I. Sokulsky ${ }^{2}$, A. Antoniuk ${ }^{2}$, M. Rusinko ${ }^{2}$ \\ ${ }^{1}$ National University of life and environmental sciences of Ukraine, Kyiv, Ukraine \\ ${ }^{2}$ Polissya National University, Zhytomyr, Ukraine
}

Article info

Received 04.10.2021

Received in revised form 08.11 .2021

Accepted 09.11.2021

National University of Life and Environmental Sciences of

Ukraine, Heroyiv Oborony Str., 15

Kyiv, 03041, Ukraine.

Tel.: +38-067-725-65-07

E-mail:nickvet@ukr.net

Polissia National University, Stary Boulevard, 7, Zhytomyr, 10008, Ukraine.

E-mail: sokulskiy_1979@ukr.net
Radzikhovskyi, M., Nedosekov, V., Dyshkant, O., Sokulsky, I., Antoniuk, A., \& Rusinko, M. (2021). Integrated indices as a criterion for evaluation of the level of endogenous intoxication for leptospirosis in dogs. Scientific Messenger of Lviv National University of Veterinary Medicine and Biotechnologies. Series: Veterinary sciences, 23(104), 77-83. doi: 10.32718/nvlvet10413

One of the most important directions in the development of modern veterinary medicine is the improvement and implementation of modern methods of diagnosis and prognosis of diseases based on determining the degree of dysfunction and the possibility of correcting the protective functions of the body. for most veterinary clinics, the study of the immunological status of animals is not available, and clinical blood tests make it possible to determine the assessment of the functional state of the immune system by integrated hematological parameters. In the article on the basis of blood formulas that reflect the state of neurohumoral homeostasis and immunological reactivity of the organism, for the first time investigated and established violations of humoral and cellular immune systems, micro- and macrophage systems, reduced nonspecific protection and found relationships between immunity in 23 dogs with leptospirosis, which calculated 19 markers of inflammatory activity, endogenous intoxication, adaptation, nonspecific and immune reactivity. The study was conducted in veterinary clinics in zhytomyr and kyiv, blood for the study was taken from the superficial vein of the forearm $v$. anterbrachium, medial subcutaneous vein or subcutaneous tibial vein v. saphena. Diagnostic studies to confirm leptospirosis were performed using rapid tests Combo Test IgG Ab/IgM Ab, vetlaboratories and elisa on the basis of a private veterinary laboratory of Llc "Bald" in Kiev. The interpretation of integrated leukocyte blood parameters revealed the development of autoimmune processes with suppression of cellular immunity and the development of endogenous intoxication, which indicates an increase in total $(P<0.01)$, leukocyte $(P<0.05)$ and nuclear index $(P<0.001)$. Suppression of the immune response and increased hypersensitivity of the immediate type based on a decrease in non-specific reactivity by $P<0.001$ and inflammation index by $P<0.05$. It is proved that integrated hematological parameters of peripheral blood increase the informativeness of the general analysis of blood in dogs with infectious diseases and allow to determine not only the degree of reactivity of the organism, but also to assess the level of endogenous intoxication.

Key words: canine leptospirosis, hematological parameters, integral indices, endogenous intoxication, immunoreactivity indicators.

\section{Інтегральні індекси як критерій оцінки рівня ендогенної інтоксикації за лептоспірозу у собак}

\author{
М. Л. Радзиховський ${ }^{1}$, В. В. Недосєков ${ }^{1}$, О. В. Дишкант ${ }^{2}$, I. М. Сокульський ${ }^{2}$, А. А. Антонюк ${ }^{2}$ \\ М. Л. Русінко ${ }^{2}$
}

${ }^{1}$ Національний університет біоресурсів і природокористування, м. Київ Украӥни

${ }^{2}$ Поліський національний університет, м. Житомир, Украӥна 
Одним з найважливіших напрямів розвитку сучасної ветеринарної медицини є удосконалення та впровадження сучасних методів діагностики й прогнозування перебігу захворювань на основі визначення ступеня порушення функиіональної активності та можливості корекції захисних функиій організму. Для більшості ветеринарних клінік, є не доступним дослідження імунологічного статусу тварин, тоді як клінічний аналіз крові надає можливість визначити оцінку функціонального стану імунної системи за інтегральними гематологічними індексами. У статті на основі формули крові, цчо відображають стан нейро-гуморального гомеостазу та імунологічної реактивності організму вперше вивчені й встановлені порушення гуморальної та клітинної ланок імунної системи, мікро- та макрофагальної системи, зниження неспецифічного захисту організму і виявлені зв'язки між інтегральними гематологічними показниками та показниками імунітету у 23 собак хворих на лептоспіроз в яких розрахували 19 маркерів активності запалення, ендогенної інтоксикації, адаптації, неспецифічної та імунної реактивності. Дослідження проводили у ветеринарних клініках міста Житомир та Киї, кров для досліджень відбирали з поверхневої вени передпліччя v. Аntегbraсhіит, медіальної вени сафена або підшкірної вени гомілки v. Sарһепа. Діагностичні дослідження на підтвердження лептоспірозу проводили за допомогою експрес тестів Cотbо Test IgG Ab/ IgM Ab, VetLaboratories та в IФА на базі приватної ветеринарної лабораторії ТОВ “Бальд” міста Києва. При інтерпретації показників інтегральних лейкоцитарних індексів крові встановлено розвиток аутоімунних прочесів з пригніченням клітинної ланки імунітету і розвитком ендогенної інтоксикації про, щзо свідчить збільщення показників загального $(P<0,01)$, лейкоцитарного $(P<0,05)$ та ядерного індексів і показника інтоксикації на $(P<0,001)$. Характерним виявлено пригнічення імунної відповіді і посилення гіперчутливості негайного типу на основі зниження індексів неспецифічної реактивності на $P<0,001$ та індексівактивності запалення на $P<0,05$. Доведено, шо інтегральні гематологічні показники периферичної крові підвищують інформативність загального аналізу крові у собак при інфекційних хворобах і дозволяють визначити не тільки ступінь реактивності організму, а й оцінити рівень ендогенної інтоксикацї.

Ключові слова: лептоспіроз собак, гематологічні показники, інтегральні індекси, ендогенна інтоксикація, показники імунореактивності.

\section{Вступ}

Забезпечення сталого розвитку наукового потенціалу України є створення і запровадження інновацій в усіх сферах так за допомогою аналізу інтегральних лейкоцитарних індексів на основі формули крові, що відображають стан нейро-гуморального гомеостазу та імунологічної реактивності організму можливе вивчення і встановлення порушення гуморальної та клітинної ланок імунної системи, мікро- та макрофагальної системи за інфікування лептоспірозом (Mohylenets', 2015; Radzykhovs'kyy et al., 2018; Borysov et al., 2021).

За даними МЕБ в останні роки спостерігається тенденція до зростання лептоспірозу серед домашніх тварин. Україна перебуває в групі країн зі складною епізоотичною ситуацією щодо цього захворювання (Hrytsyk \& Levkivs'kyy, 2010; Turchenko \& Zon, 2018). Лептоспіроз - це зоонозне захворювання, поширене у всьому світі, яке вражає більшість видів ссавців, клінічний прояв часто реєструється у собак і інколи у кішок (Pinto et al., 2017). Усі тварини, які заражені лептоспірозом, в тому числі домашні, несуть безпосередню загрозу для людей, адже можуть виділяти збудника 3 сечею, що становить висока ймовірність інфікування людини. (Schuller et al., 2015; Ngasaman et al., 2020). Особливу небезпеку становлять тварини бактеріоносії, без прояву клінічних ознак є джерелом збудника (Murphy, 2018).

Лептоспіроз зазвичай має гострий перебіг з вираженою інтоксикацією, внаслідок ураження нирок та печінки (Yavors'kyy et al., 2007). За лептоспірозу для розробки та корекції лікування є важливим визначення ендогенної інтоксикації, виразність якого визначає тяжкість і прогноз хвороби, адже за даної хвороби є складний патогенез який і пов'язаний із дією екзо- та ендотоксинів спірохет, так і з вторинними метаболічними порушеннями життєво важливих органів, що призводить до функціональної недостатності систем детоксикації (Kryshtal' et al., 2020; Zamagni et al., 2020). Рання діагностика гострого лептоспірозу все ще залишається серйозною проблемою у собак. Собак зараховували на основі повідомленого впливу відомих факто- рів ризику та клінічної картини (гостра травма нирок та/або синдром системної запальної реакції з ураженням багатьох органів) (Troìa et al., 2018).

Важливим для вивчення особливо небезпечних 3оонозів лишається клініко-діагностична інформативність, адже закордонні дослідники виявляли антитіла до лептоспірозу у невакцинованих собак, це створює значну загрозу для людства (Ojha et al., 2018), тому наукові пошуки щодо більш глибокого розуміння патогенезу лептоспірозу у собак $\epsilon$ актуальним і необхідним. У зв'язку з цим метою наших досліджень було встановити можливість оцінки ендогенної інтоксикації у собак за лептоспірозу на основі показників лейкоцитарних індексів їх крові.

Метою даної роботи було вивчити інформативність та діагностичну значущість інтегральних лейкоцитарних індексів, що характеризують ендогенну інтоксикацію за лептоспірозу у собак.

\section{Матеріал і методи досліджень}

Роботу виконували на факультетах ветеринарної медицини Національного університету біоресурсів і природокористування України та Поліського національного університету, а також у ветеринарних клініках міста Житомир та Київ на породних і безпородних собаках $(\mathrm{n}=23)$, кров для досліджень відбирали 3 поверхневої вени передпліччя $v$. Anterbrachium, медіальної вени сафена або підшкірної вени гомілки $v$. Saphena. Для розрахунку достовірності використовували референтні показники клінічно здорових собак у кількості десять голів.

Діагностичні дослідження, в умовах клініки ветеринарної медицини, на підтвердження лептоспірозу проводили за допомогою експрес тестів Combo Test $\operatorname{Ig} G \mathrm{Ab} / \operatorname{Ig} M \mathrm{Ab}$, VetLaboratories. Також діагностичні дослідження на підтвердження лептоспірозу проводили в приватній ветеринарній лабораторії $B A L D$ методом ІФА. Гематологічні методи дослідження проводили за загально прийнятими методиками підрахунку у камері Горяєва. Підрахунок лейкоцитів, лейкограми 
та швидкість осідання еритроцитів (ШОЕ) проводили електронно-автоматичним методом. На основі отриманих даних розраховано інтегральні гематологічні показники.

Рівень неспецифічного імунітету організму оцінювали на основі лейкоцитограми периферійної крові і показників ШOE (Lobo, 2017).

Розрахунок інтегральних індексів проводили згідно 3 методичними рекомендаціями (Godlevsky \& Savolyuk, 2015; Horal's'kyy et al., 2018).

Цифрові дані обробляли біометрично загальноприйнятими методами варіаційної статистики з використанням комп'ютерних програм Statistika 6.0 та Microsoft Excel 2007, та методами статистики за допомогою критерію Стьюдента (Kochetov, 2012).

Забір крові для визначення морфологічних показників крові проводили із дотриманням біоетичних вимог щодо ставлення до тварин і відповідно до Закону України "Про захист тварин від жорстокого поводження” (2006) та Європейської конвенції “Про захист тварин" (1987).

\section{Таблиця 1}

Лейкоцитарна формула у собак за лептоспірозу $(\mathrm{M} \pm \mathrm{m})$
Виконане дослідження $€$ частиною науководослідної роботи кафедри анатомії і гістології факультету ветеринарної медицини Поліського національного університету: "Маркерні ознаки розвитку органів імуногенезу та нервової системи хребетних тварин в онтоі філогенезі”, № державної реєстрації 0120U102370.

\section{Результати та їх обговорення}

Діагностичні та прогностичні можливості розрахункових гематологічних лейкоцитарних індексів набувають у цей час все більшу значущість, оскільки певні поєднання показників крові відображають інтегральні характеристики гомеостатичних систем організму, яка формує неспецифічні адаптаційні реакції. Для оцінки рівня ендогенної інтоксикації в організмі собак за лептоспірозу ми використовували клінічні показники периферичної крові. На їх основі були розраховані інтегральні гематологічні індекси інтоксикації.

\begin{tabular}{cccc}
\hline Показники & & Контроль & Дослід \\
ШоЕ & & $4,4 \pm 0,5$ & Хворі на лептоспіроз $(\mathrm{n}=23)$ \\
Лейкоцити & & $9,4 \pm 0,2$ & $9,1 \pm 2,3$ \\
& Ю & 0 & $19,3 \pm 2,1 * * *$ \\
нейтрофіли & $П$ & $1,7 \pm 0,4$ & $1,1 \pm 0,3$ \\
& $\mathrm{C}$ & $73,6 \pm 5,8$ & $6,7 \pm 0,9^{* * *}$ \\
еозинофіли & & $1,8 \pm 0,3$ & $44,7 \pm 4,3^{* * *}$ \\
базофіли & & $0,4 \pm 0,2$ & $3,4 \pm 0,7 *$ \\
лімфоцити & & $35 \pm 1,3$ & $0,3 \pm 0,1$ \\
моноцити & & $3 \pm 0,2$ & $32,4 \pm 4,7$ \\
\end{tabular}

Примітка: ${ }^{*}-\mathrm{P}<0,05 ; * *-\mathrm{P}<0,01 ; * * *-\mathrm{P}<0,001-$ порівняно зі здоровими тваринами

Відомо, що лейкоцитарна формула є інтегральним показником балансу всіх гомеостатичних систем організму. Причиною лейкоцитарних перебудов часто $\epsilon$ загальна мобілізація захисних механізмів організму, i так за лептоспірозу у собак (табл. 1) встановлено достовірне $(\mathrm{P}<0,001)$ збільшення кількості лейкоцитів. Встановлено достовірне збільшення $(\mathrm{P}<0,01)$ кількості паличкоядерних нейтрофілів, а кількість сегментоядерних зменшувалась (Р < 0,01), що на нашу думку свідчить про імунну реактивність організму за впливу чужорідного агента - спірохету. Підвищення кількості паличкоядерних на фоні зниження сегментоядерних нейтрофілів (зсув лейкоцитарної формули вліво) характеризує запальний процес 3 розвитком інтоксикації організму. Сегментоядерні нейтрофіли виконують важливу роль у процесі придушення активності бактерій за рахунок вмісту спеціальних білків, що володіють властивостями антибіотиків, тому зниження їх кількості викликає занепокоєння та передбачає корекцію етіотропної терапї (Ojha et al., 2018; Kim et al., 2019; Radzykhovs'kyy et al., 2019). Достовірне підвищення кількості еозинофілів $(\mathrm{P}<0,05)$ притаманно для розвитку алергічного стану. Моноцити першими зустрічають антиген і як найважливіші клітини імун- ної системи виконують функцію остаточного знищення чужорідних клітин та білків, осередків запалення, тому підвищення їх кількості $(\mathrm{P}<0,001)$ свідчить про запальний процес спровокований лептоспірозом (табл. 1).

За результатами дослідження інтегральних індексів інтоксикації у собак за лептоспірозу (табл. 2) встановлено достовірне збільшення (P < 0,001) таких величин як ядерного індексу (ЯІ) на $66 \%$, реактивної відповіді нейтрофілів (РВН) більш ніж у чотири рази, показника інтоксикації (ПІ) втричі, та на $10 \%$ $(\mathrm{P}<0,05)$ лейкоцитарного індексу (ЛІ). достовірне зниження (P $<0,001)$ таких величини як індексу зсуву лейкоцитів крові (ІЗЛК) на $27 \%$ та лейкоцитарного індексу інтоксикації (ЛІІ) на 25 \% що до контрольної групи й свідчить про системну імунну відповідь на гострий запальний процес 3 порушенням імунореактивності та надходження у периферійну кров великої кількості “молодих" форм лейкоцитів, розвиток домінування гуморальної ланки імунітету над клітинною i декомпенсацією ендогенної інтоксикації, при цьому загальний стан організму $\epsilon$ середньої важкості (Khabirov, 2002; Grin et al., 2006; Ostrovskiy et al., 2006; Godlevsky \& Savolyuk, 2015; Kiiko, 2018). 


\section{Таблищя 2}

Інтегральні індекси інтоксикації у собак за лептоспірозу $(\mathrm{M} \pm \mathrm{m})$

\begin{tabular}{ccc}
\hline Показники & Контроль & Дослід \\
& Здорові тварини $(\mathrm{n}=10)$ & Хворі на лептоспіроз $(\mathrm{n}=23)$ \\
\hline ЛІІ & $1,6 \pm 0,04$ & $1,2 \pm 0,03^{* * *}$ \\
ЯІ & $0,06 \pm 0,001$ & $0,4 \pm 0,01^{* * *}$ \\
РВН & $1,1 \pm 0,08$ & $4,6 \pm 0,72^{* * *}$ \\
IЗЛК & $1,9 \pm 0,04$ & $1,4 \pm 0,21^{* * *}$ \\
ЛІ & $0,54 \pm 0,01$ & $0,6 \pm 0,03^{*}$ \\
ПІ & $0,05 \pm 0,005$ & $0,16 \pm 0,01^{* * *}$ \\
\hline
\end{tabular}

Примітка: * $-\mathrm{P}<0,05 ;$ ** $-\mathrm{P}<0,01 ; * * *-\mathrm{P}<0,001$ - порівняно зі здоровими тваринами

Таблиця 3

Інтегральні індекси неспецифічної реактивності у собак за лептоспірозу $(\mathrm{M} \pm \mathrm{m})$

\begin{tabular}{ccc}
\hline Показники & Контроль & Дослід \\
Здорові тварини $(\mathrm{n}=10)$ & Хворі на лептоспіроз $(\mathrm{n}=23)$ \\
\hline ІСНЛ & $1,9 \pm 0,03$ & $1,6 \pm 0,12^{*}$ \\
ІСНМ & $30,1 \pm 3,1$ & $6,3 \pm 1,2^{* * *}$ \\
ІСЛМ & $16,1 \pm 1,5$ & $3,9 \pm 0,8^{* * *}$ \\
IСЛЕ & $9,3 \pm 1,03$ & $9,8 \pm 1,7$ \\
ІСЕЛ & $0,13 \pm 0,02$ & $0,11 \pm 0,07^{*}$ \\
IГ & $0,6 \pm 0,08$ & $0,7 \pm 0,12$ \\
ІА & $1,7 \pm 0,05$ & $1,3 \pm 0,06^{* * *}$ \\
IІР (Іванову) & $17,8 \pm 1,6$ & $4,4 \pm 0,3^{* * *}$ \\
ІСНПН & $34,4 \pm 3,1$ & $6,7 \pm 0,9^{* * *}$ \\
\hline
\end{tabular}

Примітка: *-P <0,05; ** - $\mathrm{P}<0,01 ; * * *-\mathrm{P}<0,001-$ порівняно зі здоровими тваринами

При інтерпретації інтегральних гематологічних індексів неспецифічної реактивності у собак за лептоспірозу (табл. 3) встановлено їх достовірне зменшення на $(\mathrm{P}<0,001)$ індекс співвідношення нейтрофілів і моноцитів (ICHM) майже у п'ять разів, індекс співвідношення лімфоцитів і моноцитів (ІСЛМ) вчетверо, індекс алергізації (IA) на $24 \%$, індекс імунореактивності за Івановим (IIP) вчетверо та індекс співвідношення сегментоядерних та паличкоядерних нейтрофілів (ICHПН) майже у п'ять разів, індексу співвідношення еозинофілів і лімфоцитів (ICEЛ) індексу співвідношення нейтрофілів i лімфоцитів (ICHЛ) або (індекс Кребса) на 26 \% (P < 0,05), що до контрольної групи та свідчить про домінування специфічного захисту за рахунок активності фагоцитарних реакцій на тлі порушення взаємодії афекторної й ефекторної ланок імунної системи і провокує ослаблення чутливості організму до чужорідних речовин і вказує на пригнічення імунної системи, а саме нестачу блокаторів запалення (Ivanov et al., 2002; Schaudien, 2010; Derkho \& Samoylova, 2011; Gutyj et al., 2017; Sakovich, 2012; Bel'skaya et al., 2016). Розвиток інфекційного процесу у хворих собак також призводить до динамічного зниження величини індексу співвідношення сегментоядерних нейтрофілів та паличкоядерних нейтрофілів, що свідчить про гіпофункцію підшлункової залози (Ivashchuk, 2014; Terzungwe, 2018).

\section{Таблиця 4}

Інтегральні індекси активності запалення у собак за лептоспірозу $(\mathrm{M} \pm \mathrm{m})$

\begin{tabular}{ccc}
\hline Показники & Контроль & Дослід \\
Здорові тварини $(\mathrm{n}=10)$ & Хворі на лептоспіроз $(\mathrm{n}=23)$ \\
\hline ІСЛШОЕ & $0,5 \pm 0,2$ & $1,8 \pm 0,5^{*}$ \\
ІЛГ & $4,9 \pm 0,2$ & $5,7 \pm 0,6$ \\
ІСЛМШОЕ & $9,9 \pm 0,25$ & $4,6 \pm 0,53 * * *$ \\
ЗІ & $5,8 \pm 0,16$ & $10,3 \pm 1,71^{* *}$ \\
\hline
\end{tabular}

Примітка: * $-\mathrm{P}<0,05 ; * *-\mathrm{P}<0,01 ; * * *-\mathrm{P}<0,001-$ порівняно зі здоровими тваринами

За інтерпретації показників інтегральних гематологічних індексів активності запалення у собак за лептоспірозу (табл. 4), встановлено достовірне $(\mathrm{P}<0,001)$ зменшення величини показників індексу співвідношення лейкоцитів i моноцитів до ШОЕ (ІСЛМШОЕ) майже вдвічі, та достовірне збільшення $(\mathrm{P}<0,05)$ індексу співвідношення лейкоцитів і ШОЕ (ICЛШОЕ) майже втричі та на $(\mathrm{P}<0,01)$ загального індексу (3І) вдвічі, що, свідчать про пригнічення імунної відповіді й розвиток запального процесу, наявність інтоксикації, що зумовлена мікробним чинником (ендо- та екзотоксинами) та розвиток аутоімунних процесів (Ostrovskiy et al., 2003; Bel'skaya et al., 2016; Radzykhovs'kyy et al., 2019). 


\section{Висновки}

У собак за лептоспірозу встановлено достовірне збільшення ЯІ та ПІ на $\mathrm{P}<0,001$, ЛІ й ІСЛШОЕ на $\mathrm{P}<$ 0,05 та 3І на $\mathrm{P}<0,01$, що свідчить за системну імунну відповідь на гострий запальний процес який провокує виснаження імунної системи та розвиток аутоімунних процесів на тлі активації гуморальної ланки імунітету і декомпенсації ендогенної інтоксикації, яка зумовлена інфекційним процесом, а саме мікробними чинниками - токсинами. Враховуючи достовірне зниження IA, ICЛМ, ICHМ, IIP на P $<0,001$ та ICHЛ на $\mathrm{P}<0,05$ і збільшення ІСЛЕ, що характеризується пригніченням імунної відповіді, а саме порушення взаємодії афекторних і ефекторних ланок імунітету, що призводить до нестачі блокаторів запалення - дефіцит цитокінів і зниження рівня фагоцитарного захисту та перевагу специфічного імунітету на тлі посилення гіперчутливості негайного типу. Отже, проведені комплексні дослідження вказали, що застосування інтегральних індексів математичних показників лейкоцитарної формули венозної крові можуть розширити можливості отримання інформації щодо імунологічної реактивності організму тварин, діагностувати запальні та інфекційні процеси, що протікали нещодавно або в момент дослідження у різних органах і системах, а також визначити стратегію подальших лікувальних або профілактичних заходів спрямованих на досягнення позитивного ефекту.

Відомості про конфлікт інтересів. Автори стверджують про відсутність конфлікту інтересів щодо їх вкладу та результатів досліджень.

\section{References}

Bel'skaya, L. V., Kosenok, V. K., \& Massard G. (2016). Endogenous intoxication and sebum lipid peroxidation in patients with lung cancer J. Diagnostics, 6(4), 39. doi: 10.3390/diagnostics6040039.

Borysov, S. O., Kostyev, F. I., Borysov, K. O., \& Kolosov O. M. (2021). Znachymist' intehral'nykh indeksiv intoksykatsiyi yak kryteriyi otsinky rivnya endohennoyi intoksykatsiyi ta efektyvnosti medykamentoznoho vplyvu za umov modelyuvannya hostroho piyelonefrytu na tli suputn'oyi yomu hiperhlikemichnoho stanu [Significance of integrated intoxication indices as criteria for assessing the level of endogenous intoxication and the effectiveness of drug exposure in the simulation of acute pyelonephritis on the background of concomitant hyperglycemic state]. Urolohiya, 25(3), 180-192. doi: 10.26641/2307-5279.25.3.2021.241646 (in Ukrainian).

Derkho, M. A., \& Samoylova, Ye. S. (2011). Integral intoxication indices as a criterion for assessing the level of endogenous intoxication in babesiosis [Integral'nyye indeksy intoksikatsii kak kriteriy otsenki urovnya endogennoy intoksikatsii pri babezioze] Uchenyye zapiski KGAVM im. N. E. Baumana, 207, 170-177 (in Russian).
Dovhiy, YU. YU., Radzykhovs'kyy, M. L., Dubova, O. A., Feshchenko, D. V., Nikitin, O. A., Bakhur, T. I., Dyshkant, O. V., \& Dovhiy M. YU. (2016). Parazytarni ta infektsiyni khvoroby m"yasoyidnykh tvaryn [Parasitic and infectious diseases of carnivorous animals] : navch. posibnyk / pod red. YU. YU. Dovhiya; vyd. 2-he, per. i dop. Zhytomyr: Polissya (in Ukrainian).

Godlevsky, A. I., \& Savolyuk, S. I. (2015). Diagnostika ta monitoring endotoksikozu u xirurgichnix xvorix [Diagnosis and monitoring of endotoxicosis in surgical patients] Vinnitsa: The New Book (in Ukrainian).

Grin, V. K., Fistal, E. Ya., \& Speransky, I. I. (2006). Integralnye gematologicheskie pokazateli lejkocitarnoj formuly kak kriterij ocenki tyazhesti techeniya ozhogovoj bolezni, ee oslozhnenij i effektivnosti provodimogo lecheniya [Integral hematological parameters of leukocyte formula as a criterion for assessing the severity of the course of a burn disease, its complications and the effectiveness of the treatment being performed]. Materials of the scientific-practical. conf. "Sepsis: Problems of Diagnosis, Therapy and Prevention", March 29-30, Kharkiv, 77-78 (in Russian).

Gutyj, B., Grymak, Y, Drach, M., Bilyk, O., Matsjuk, O., Magrelo, N., Zmiya, M., \& Katsaraba, O. (2017). The effect of endogenous intoxication on the biochemical indices of blood of pregnant cows. Regulatory Mechanisms in Biosystems, 8(3), 438-443. doi: 10.15421/021768.

Horal's'kyy, L. P., Radzykhovs'kyy, M. L., \& Dyshkant, O. V. (2018). Intehral'ni hematolohichni indeksy otsinky stupenya endohennoyi intoksykatsiyi u sobak [Integral hematological indices for assessing the degree of endogenous intoxication in dogs]. Metodychni rekomendatsiyi. Zhytomyr (in Ukrainian).

Hrytsyk, T. M., \& Levkivs'kyy, D. M. (2010). Leptospiroz sobak - diahnostychni i terapevtychni aspekty. [Canine leptospirosis - diagnostic and therapeutic aspects]. Naukovyy visnyk LNUVM ta BT im. S. Z. Gzhyts'koho. L'viv, 12(3(45)), 45-49 (in Ukrainian).

Ivanov, D. O., Shabalov, N. P., \& Shabalova, N. N. (2002). Leukocyte indices of cellular reactivity as an indicator of the presence of hypo-and hyper-allergic variants of neonatal sepsis [Leykotsitarnyye indeksy kletochnoy reaktivnosti kak pokazatel' nalichiya gipoi giperergicheskogo variantov neonatal'nogo sepsisa] Opyt lecheniya detey $\mathrm{v}$ mnogoprofil'noy detskoy bol'nitse : sb. SPb. 22-28 (in Russian).

Ivashchuk, S. I. (2014). Reaktyvna vidpovid' polimorfnoyadernykh neytrofil'nykh hranulotsytiv peryferiynoyi krovi khvorykh na hostryy pankreatyt zalezhno vid genezu [Reactive response of polymorphonuclear neutrophilic granulocytes of peripheral blood of patients with acute pancreatitis depending on the genesis]. Ukraynskyy zhurnal khyrurhyy, 3-4(2627), 86-93 (in Ukrainian).

Khabirov, T. SH. (2002) Uroven' reaktivnogo otveta neytrofilov kak pokazatel' stepeni tyazhesti endogennoy intoksikatsii pri abdominal'nom sepsise [The level of reactive response of neutrophils as an indicator of the severity of endogenous intoxication in 
abdominal sepsis]. Trudi ÍKH kongresu SFULT: Lugans'k (in Ukrainian).

Kiiko, G. (2018). Intehral'ni pokaznyky leykohramy v otsintsi stanu zdorov"ya porosyat za hipoplastychnoyi anemiyi [Integral indicators of the leukogram in the assessment of the health of piglets with hypoplastic anemia]. Veterynariya, tekhnolohiyi tvarynnytstva ta pryrodokorystuvannya, 2, 39-42. doi: 10.31890/vttp.2018.02.10 (in Ukrainian).

Kim, T. Y., Kim, S. J., Kim, Y. S., Lee, J. W., Park, E. J., Lee, S. J., Lee, K. J., \& Cha, Y. S. (2019). Delta neutrophil index as an early predictive marker of severe acute pancreatitis in the emergency department United European Gastroenterol Journal, 7(4), 488495. doi: 10.1177/2050640619838359.

Kochetov, A. G., Lyang, O. V., Masenko, V. P., Zhirov, I. V., Nakonechnikov, S. N., \& Tereshchenko, S. N. (2012). Metody statisticheskoj obrabotki medicinskix dannyx: metodicheskie rekomendacii dlya ordinatorov i aspirantov medicinskix uchebnyx zavedenij, nauchnyx rabotnikov [Methods of statistical processing of medical data: Methodical recommendations for interns and post-graduate students of medical educational institutions, scientific workers]. Moscow: RKNPK (in Russian).

Kryshtal', M. V., Hozhenko, A. I., \& Sirman, V. M. (2020). Patofiziolohiya nyrok [Pathophysiology of the kidneys]. Odesa: Feniks (in Ukrainian).

Lobo, A., Vinodkumar, K., Tresamol, P. V., Justin Davis, K., Priya, P. M. (2017). Hematological changes in dogs with parvovirus enteritis in thrissur district. Imperial Journal of Interdisciplinary Research, 3(6), $1323-1325$.

Mohylenets', O. I. (2015). Intehral'ni hematolohichni pokaznyky yak predyktory dotsil'nosti zastosuvannya antybakterial'noyi terapiyi u khvorykh na hostri respiratorni infektsiyi [Integral hematological indicators as predictors of expediency of application of antibacterial therapy at patients with acute respiratory infections]. Scientific Journal "ScienceRise", 10/3(15), 16-19. doi: 10.15587/2313-8416.2015.51531 (in Ukrainian).

Murphy, K. (2018). Dealing with leptospirosis in dogs. Veterinary Record, 183(12), 384-385. doi: 10.1136/vr.k4093.

Ngasaman, R., Saechan, V., Prachantasena, S., Yingkajorn, M., \& Sretrirutchai, S. (2020). Investigation of Leptospira Infection in Stray Animals in Songkhla, Thailand: Leptospirosis Risk Reduction in Human. Vector-Borne and Zoonotic Diseases, 20(6), 432-435. doi: 10.1089/vbz.2019.2549.

Ojha, K. C., Singh, D. K., Kaphle, K., Shah, Y., \& Pant, D. K. (2018). Sero-prevalence of leptospirosis and differentiation in blood parameters between positive and negative cases in dogs of Kathmandu Valley. Transactions of the Royal Society of Tropical Medicine, 112 (8), 378-382. doi: 10.1093/trstmh/try065.

Ostrovskiy, V. K., Alimov, R. R., Mashchenko, A. V., Semenova, O. P., \& Kurapova, M. I. (2003). About indicators of the norm of leukocyte index of intoxication [O pokazatelyakh normy leykotsitarnogo indeksa intoksikatsii] Klinicheskaya laboratornaya diagnostika, 1, 45-46 (in Russian).
Ostrovskiy, V. K., Mashchenko, A. V., Yangolenko, D. V., \& Makarov, S. V. (2006) Blood and leukocyte index of intoxication in assessing the severity and determining the prognosis for inflammatory, purulent and purulent-destructive diseases [Pokazateli krovi i leykotsitarnogo indeksa intoksikatsii $\mathrm{V}$ otsenke tyazhesti i opredelenii prognoza pri vospalitel'nykh, gnoynykh i gnoynodestruktivnykh zabolevaniyakh] Klin. lab. Diagnostika, 6, 50-53 (in Russian).

Pinto, P. S., Libonati, H., \& Lilenbaum, W. (2017). A systematic review of leptospirosis on dogs, pigs, and horses in Latin America. Tropical Animal Health and Production, 49(2), 231-238. doi: 10.1007/s11250-0161201-8.

Radzykhovs'kyy, M. L., Horal's'kyy, L. P., \& Dyshkant, O. V. (2019). Dynamika leykotsytarnykh indeksiv za parvovirusnoho enterytu u sobak [Dynamics of leukocyte indices in parvovirus enteritis in dogs]. Theoretical and Applied Veterinary Medicine, 7(1), 3-7. doi: 10.32819/2019.71001 (in Ukrainian).

Radzykhovs'kyy, M. L., Horal's'kyy, L. P., Borysevych, B. V., \& Dyshkant, O. V. (2018). Intehral'ni indeksy intoksykatsiyi u sobak za koronavirusnoho enterytu [Integral indices of intoxication in dogs with coronavirus enteritis]. Naukovyy visnyk veterynarnoyi medytsyny. Bila Tserkva, 2(144), 13-19 (in Ukrainian).

Sakovich, A. R. (2012). Hematological leukocyte indices in acute purulent sinusitis [Gematologicheskiye leykotsitarnyye indeksy pri ostrom gnoynom sinusite] UO "Belorusskiy gosudarstvennyy meditsinskiy universitet", 89-91 (in Russian).

Schaudien, D., Polizopoulou, Z., Koutin, A., Schwab, S., Porombka, D., Baumgärtner, W., \& Herden, C. (2010). Leukoencephalopathy associated with parvovirus infection in Cretaceous hound puppies. Journal of clinical microbiology, 48(9), 3169-3175. doi: 10.1128/JCM.01582-09.

Schuller, S., Francey, T., Hartmann, K., Hugonnard, M., Kohn, B., Nally, J. E., \& Sykes, J. (2015). European consensus statement on leptospirosis in dogs and cats. Journal of small animal practice, 56(3), 159-179. doi: 10.1111 jsap.12328.

Terzungwe, T. M. (2018). Hematological Parameters of Dogs Infected With Canine Parvovirus Enteritis in Sumy Ukraine. World Journal of Innovative Research, 5(3), 15. URL: https://media.neliti.com/media/publications/ 262462-hematological-parameters-of-dogs-infectebbad8caa.pdf.

Troìa, R., Balboni, A., Zamagni, S., Frigo, S., Magna, L., Perissinotto, L., Battilani, M., \& Dondi, F. (2018). Prospective evaluation of rapid point-of-care tests for the diagnosis of acute leptospirosis in dogs. Veterinary Journal, 237, 37-42. doi: 10.1016/j.tvj1.2018.05.010.

Turchenko, O. M., \& Zon, H. A. (2018). Leptospiroz sobak u m. Sumy: epizootychnyy monitorynh, diahnostyka ta likuvannya [Leptospiroz sobak u $\mathrm{m}$. Sumy: epizootychnyy monitorynh, diahnostyka ta likuvannya]. Veterynarna biotekhnolohiya. Kyyiv, 32(2), 545-550 (in Ukrainian).

Yavors'kyy, I. H., Zubach, O. O., Sel'vestr, S. P., \& Zinchuk, O. M. (2007). Hemorahichnyy syndrom pry lep- 
tospirozi [Hemorrhagic syndrome in leptospirosis]. Infektsiyni khvoroby, 4, 22-26 (in Ukrainian).

Zamagni, S., Troìa, R., Zaccheroni, F., Monari, E., Grisetti,

C., Perissinotto, L., Balboni, A., \& Dondi, F. (2020).
Comparison of clinicopathological patterns of renal tubular damage in dogs with acute kidney injury caused by leptospirosis and other aetiologies. Veterinary Journal, 266, 105573. doi: 10.1016/j.tvj1.2020.105573. 